\title{
O atual campo afro-religioso gaúcho
}

\author{
The contemporary Afro-American religion field in \\ Rio Grande do Sul
}

\author{
Ari Pedro Oro*
}

\begin{abstract}
Resumo: O artigo versa sobre o atual campo afro-religioso do Rio Grande do Sul, com destaque para as principais expressões religiosas que o compõem e os números estatísticos que se dispõe sobre ele. A análise se concentra em dois pontos: a) na grande importância que vem assumindo, nas últimas décadas, a Linha Cruzada, ou Quimbanda, neste Estado, e seus efeitos sobre o próprio campo afro-religioso; e, b) na forte incidência observada neste Estado de pertencimento a este campo religioso, fato constatado nos dois últimos censos do IBGE, e que apontam o Rio Grande do Sul como o estado mais afro-religioso do país.
\end{abstract}

Palavras-chave: batuque; Linha Cruzada; Umbanda; Rio Grande do Sul

Abstract: This article analyzes the current Afro-religious field of Rio Grande do Sul, with emphasis on its religious expressions and the statistical data available. The analysis focuses on two points: a) the strong importance that "Linha Cruzada", or Quimbanda, has acquired in that state during the last decades, and its effects on the religious field; and b) the strong incidence one observes in that state of belonging to that religious field, fact which has been verified during the last two national censuses that show Rio Grande do Sul is the most Afro-religious state of Brazil.

Keywords: "batuque"; "Linha Cruzada"; "Umbanda"; Rio Grande do Sul

Não é nossa intenção efetuar uma recuperação histórica das religiões afro-brasileiras no Rio Grande do Sul, ${ }^{1}$ mas, sim, discorrer sobre duas de suas características atuais, a saber: a importância cada vez mais crescente que está ocupando a Linha Cruzada/Quimbanda no cenário afro-religioso do Estado e a importante expressão social de pertencimento a este segmento religioso que

* Professor de Antropologia da Universidade Federal do Rio Grande do Sul (Ufrgs), doutor em Antropologia pela Universidade de Paris.<arioro@uol.com.br>.

1 Em grande medida este trabalho já foi realizado, mas não completado, por Correa, $1988 \mathrm{e}$ 1994; Lirio de Mello, 1995; Braga, 1998; Silva, 1999; Oro, 2002, entre outros.

\begin{tabular}{|l|l|l|l|l|l|}
\hline Civitas & Porto Alegre & v. 12 & n. 3 & p. 556-565 & set.-dez. 2012 \\
\hline
\end{tabular}


ocorre neste Estado, se comparado com os dados constantes em outros estados da Federação, revelados pelos últimos recenseamentos efetuados pelo IBGE, e que apontam o Rio Grande do Sul como o estado mais afro-religioso do país.

A Linha Cruzada, ou Quimbanda, constitui uma das expressões que compõem o complexo afro-religioso gaúcho, ao lado do Batuque e da Umbanda. Ela se caracteriza, fundamentalmente, pelo culto às entidades tipificadas como Exus e Pombagiras. ${ }^{2}$ Já o Batuque representa a face mais africana do complexo, pois a língua litúrgica é a nagô, os símbolos utilizados são aqueles dos antepassados, as entidades veneradas são os orixás ${ }^{3}$ e há uma identificação às "nações" africanas ${ }^{4}$. Enfim, a Umbanda, tal como no resto do país, representa o lado mais "brasileiro" das três modalidades afro-religiosas, pois consiste num importante sincretismo que agrega em seu repertório simbólico elementos do catolicismo popular, do espiritismo kardecista e das religiosidades indígenas e africanas. Seus rituais são celebrados em língua portuguesa e as entidades veneradas são, sobretudo, os "caboclos" (índios), os "pretos-velhos" e os "bejis" (crianças), além das "falanges" africanas.

No Rio Grande do Sul, há muito tempo estas três modalidades de culto ultrapassaram a fronteira étnica e se tornaram universais, sendo hoje frequentadas por indivíduos de distintos grupos étnicos e de diferentes camadas sociais (Oro, 1988).

Antes de analisarmos as duas especificidades acima apontadas, apresentamos alguns números acerca do atual campo afro-religioso gaúcho.

\section{Alguns números acerca das religiões afro-brasileiras no Rio Grande do Sul}

A estatística acerca das religiões afro-rio-grandenses constitui uma lacuna ainda não preenchida. Estima-se a existência neste Estado de cerca de

2 Os Exus mais celebrados na Quimbanda gaúcha são os seguintes: Tíriri, Marabô, Sete Cruzeiros, Destranca Ruas, Rei das Sete Encruzilhadas, Tranca Ruas, Da Porteira, Zé Pelintra, Pantera Negra, Da Capa Preta, Quebra-Galho,Ventania, Calunga, Sete Pedras, Sete Chaves, Sete Portas, Tranca Tudo, Exu do Cemitério, Caveira, Da Meia-Noite, Do Lodo, Maré. As Pombagiras mais presentes na Quimbanda do Rio Grande do Sul são: Da Estrada, Das Almas, Rainha das Sete Encruzilhadas, Das Sete Saias, Maria Padilha, Cigana do Acampamento, Do Oriente, Rosa Vermelha, Maria Quitéria, Maria Mulambo, Da Praia, Cigana da Praia e Tucuara.

3 O Batuque cultua doze orixás, a saber: Bará, Ogum, Iansã (ou Oiá), Xangô, Oba, Odé/Otim, Ossanha, Xapanã, Oxum, Iemanjá e Oxalá. A cada um deles são atribuídas características específicas, símbolos, animais sacrificados e correspondências com santos católicos, resultantes dos mitos relatados nas duas tradições religiosas

4 As "nações" mais importantes do Batuque rio-grandense são: Gege, Ijexá, Oió, Cabinda, Nagô e, especialmente, Geje-Ijexá. 
trinta mil terreiros, espalhados por todo o seu território, havendo, porém, uma concentração maior na região metropolitana de Porto Alegre (Correa, 2007). A maioria dos terreiros realizariam as três formas ritualísticas acima referidas, havendo, porém, um certo número de terreiros que praticam unicamente rituais de umbanda, outros, poucos, unicamente de batuque e outros, muitos, somente de Linha Cruzada. A investigação acerca da distribuição percentual nos terreiros das três modalidades religiosas ainda não foi realizada.

Quanto ao número de indivíduos que se declaram pertencentes às religiões afro-brasileiras, chamou a atenção no recenseamento realizado pelo IBGE no ano 2000, o fato de o Rio Grande do Sul aparecer como o Estado brasileiro em que, em termos proporcionais, mais indivíduos disseram pertencer a essas religiões. Era, então, 1,62\% da população gaúcha, contra $1,31 \%$ da população do Estado do Rio de Janeiro, que ocupava o segundo lugar. A Bahia aparecia somente com $0,08 \%$ da população que se declarou seguidora das religiões afro-brasileiras. No Brasil como um todo, $0,3 \%$ da população se manifestou como pertencente ao segmento religioso afro-brasileiro.

No Censo de 2010, realizado também pelo IBGE, a média nacional de identificação de pertencimento ao segmento afro-religioso se manteve em $0,3 \%$ da população. Novamente o Rio Grande do Sul apareceu como o Estado com o índice mais elevado de indivíduos que se declararam pertencentes às religiões afro-brasileiras. Desta feita, o Rio Grande do Sul também aparece como recordista nacional em números absolutos de indivíduos vinculados às religiões afro-brasileiras. De fato, são 157.599 indivíduos deste Estado, o que corresponde, a $1,47 \%$ da população total, que reivindicaram o seu pertencimento religioso afro-brasileiro. Esta porcentagem sobe para 2,52\% se tomarmos como referência a Região Metropolitana de Porto Alegre e para $3,35 \%$ se nos restringirmos somente a Porto Alegre. Ainda segundo o Censo 2010, a porcentagem de pertencimentos afro-religiosos no estado do Rio de Janeiro baixou para 0,89 e da Bahia subiu para $0,34 \%$, igualando a São Paulo, constituindo-se, Bahia e São Paulo como sendo o segundo e o terceiro estados com maior representatividade afro-religiosa. Os demais estados de reconhecida existência dessas religiões apresentaram os seguintes índices: Pará $0,07 \%$, Maranhão, $0,06 \%$ e Pernambuco $0,14 \%$.

Como escrevemos em outro lugar (Oro, 2008), se levarmos em conta o que revelaram outras pesquisas, esses números subestimam ao menos pela metade a realidade demográfica dessas religiões no país. Isto se deve, segundo R. Prandi, 
[...] às circunstâncias históricas nas quais essas religiões se constituíram no Brasil e ao seu caráter sincrético daí decorrente [...]. Por tudo isto, é muito comum, mesmo atualmente, quando a liberdade de escolha religiosa já faz parte da vida brasileira, muitos seguidores das religiões afro-brasileiras ainda se declararem católicos (Prandi, 2003, p. 16).

Seja como for, mais à frente avançaremos algumas hipóteses para explicar a importante incidência de indivíduos que expressam o seu pertencimento identitário afro-religioso no Rio Grande do Sul.

Voltando aos números, e visando suprir a lacuna da ausência de estatísticas acerca das religiões afro-brasileiras no Rio Grande do Sul, a Prefeitura Municipal de Porto Alegre, atendendo uma reivindicação da comunidade afrobrasileira, solicitou ao Centro de Pesquisa Histórica, da Secretaria Municipal de Cultura, a realização de um Censo das Casas de Religião Afro de Porto Alegre. ${ }^{5}$ Ele ocorreu entre os anos de 2006 e 2008 e apontou a existência de 1.290 terreiros em Porto Alegre. Este número é praticamente o mesmo de Salvador da Bahia, posto que um recenseamento, realizado nesta cidade, em 2007, identificou 1.296 terreiros (Santos, 2008).

$\mathrm{Na}$ sequência nos ocupamos das questões que cercam a chamada Linha Cruzada no Rio Grande do Sul. Importa entender as razões do seu sucesso e evidenciar algumas polêmicas que envolvem a sua presença e reprodução neste Estado.

\section{A Quimbanda no Rio Grande do Sul: controvérsias e sucesso}

Entre as três formas religiosas acima mencionadas a Linha Cruzada, ou Quimbanda, é a que detém hoje maior espaço de reprodução e poder de atração social. Ela foi a última a ser implantada no Estado e está aumentando sensivelmente o número de terreiros que a cultuam.

De fato, o Batuque teria sido a primeira expressão afro-religiosa a ser estruturada no Estado, ainda na primeira metade do século 19, nas cidades de Pelotas e de Rio Grande, espalhando-se dali para o resto do Estado (Lirio de Mello, 1995; Correa, 1988; Braga, 1998). ${ }^{6}$ Floresceu, segundo N. Correa (1994), num estado eminentemente agrário e pastoril, que permitia a realização

5 Os resultados deste Censo ainda não vieram a público. Certamente que quando isto ocorrer teremos muitas informações relevantes sobre as religiões de matriz africana na capital gaúcha.

6 Quanto ao mito fundador do batuque, há duas versões correntes: uma que afirma ter sido ele trazido para o Rio Grande do Sul por uma escrava vinda de Pernambuco; outra que não associa a um personagem mas às etnias africanas que o estruturaram enquanto espaço de resistência simbólica à escravidão. 
de longas iniciações religiosas, já que as relações de trabalho eram ainda relativamente frouxas.

A Umbanda também teria iniciado em Rio Grande, em 1926, quando o ferroviário Otacílio Charão fundou o centro chamado "Reino de São Jorge". Foi trazida para Porto Alegre em 1932, pelo capitão da marinha Laudelino de Souza Gomes, que fundou nesta capital a Congregação Espírita dos Franciscanos de Umbanda, existente até os dias atuais (Oro, 2002).

$\mathrm{Na}$ década de 1930 o capitalismo encontrava-se numa fase adiantada no Rio Grande do Sul: a economia se monetarizava, iniciava-se o processo de industrialização, já ocorria o êxodo rural. O tempo tomava nova dimensão. As pessoas centravam suas vidas em torno do trabalho. A Umbanda se adequou aos novos tempos: a duração dos seus rituais é menor do que a do batuque, não se faz uso de tambores e não são realizados sacrifícios de animais. Dessa forma, os fiéis podem cumprir suas obrigações religiosas sem alterar o seu ritmo do cotidiano.

Enfim, a Linha Cruzada teria iniciado na década de 1970, numa fase de consolidação do capitalismo, com o consequente incremento de graves problemas, tais como desemprego, insegurança, doenças, aflições de toda ordem. Desde então, a Linha Cruzada/Quimbanda se afirmou como a forma religiosa predominante no meio afro-religioso rio-grandense (Correa, 1994).

Porém, a proliferação de terreiros cruzados ou de rituais de exubandeiros não ocorreu de forma pacífica e tranquila no Rio Grande do Sul. Ao contrário, foi e continua sendo objeto de tensões e polêmicas na comunidade afroreligiosa sul-rio-grandense.

As controvérsias expressam, sobretudo, conflitos intergeracionais, posto que são geralmente os "mais velhos" na "religião" que tendem a considerar a exacerbação da presença da Quimbanda como uma "deturpação" levada a frente especialmente pelos mais jovens; expressa também conflitos ideológicos entre conservadores, que reivindicam a continuação da religião de matriz africana ou da umbanda "pura", frente às inovações conduzidas por progressistas "espertos e aproveitadores".

Um livro publicado em 2009, intitulado “Adeus aos orixás", faz eco e explicita de forma cristalina as críticas mais contundentes que são repetidas no meio afro-religioso rio-grandense contra o forte avanço da Quimbanda e do culto aos Exus e Pombagiras. De fato, o escritor afro-religioso Lindomar Alves, ${ }^{7}$ expressa nesse livro o seu desabafo, revolta e denúncia contra o que

Lindomar Alves é jornalista e radialista, primeiro escritor a publicar livros sobre cultos afros no Rio Grande do Sul. É autor de 59 livros e fundador da primeira federação de Babalorixás e Yalorixás do Rio Grande do Sul, a Afro-Bras, em 1973. 
considera o menosprezo e a marginalização do Batuque e da Umbanda em favor da Quimbanda. Afirma esse autor que respeita "os Exus, as Pombas Giras, caboclos, pretos velhos, orixás e todo o plano espiritual. Só não aceito tanta safadeza e imoralidade em nome dos Exus" (Alves, 2009, p. 52). Mais enfaticamente, sustenta que os que levam avante a Quimbanda são "aproveitadores, mentirosos e aventureiros" e que em seus rituais predominam "alcoolismo, prostituição e vícios os mais diversos" (p. 10); "belos visuais, muita festa com bebidas e profanação, quando não até imoral" (p. 33). Lamenta que "hoje impera a mentira e a mistificação" (p. 39). Resta, segundo ele, "a ira dos orixás, nesta revolta dos deuses com tantas patifarias que chamam de religião" (p. 40). Além disso, invoca as autoridades para assumirem uma atitude, estarem de alerta, fazerem a sua parte, diante da "vigarice e safadeza que extrapolou demais: alcoolismo, prostituição e drogas não tem nada a ver com religião" (p. 41).

Toda esta deturpação, segundo ele, conduziu a um só resultado: "a revolta, a ira dos orixás, os santos estão fugindo dos Ilês [...] os santos as abandonaram e se continuar assim podem dar "Adeus aos Orixás” (p. 61). E arremata: "não enlouqueci não; a verdade tem que ser dita [...]. A continuar assim podemos dar 'adeus aos orixás' e será o fim do batuque, aliás está aí o fim" (p. 63).

Mas, então, como explicar o aumento extraordinário da Quimbanda no Rio Grande do Sul, apesar das críticas severas que lhe são endereçadas, e aqui condensadas no livro acima referido?

Norton Correa propõe as seguintes razões que justificariam o grande crescimento da Linha Cruzada/Quimbanda: os custos dos rituais são mais baratos do que no batuque; o aprendizado geral é mais simples do que no Batuque; pode-se reunir e somar a força mística do Batuque com a da Umbanda (Correa, 1988, p. 90).

A estas razões acrescentamos outras, derivadas tanto de entrevistas realizadas com frequentadores da Quimbanda quanto de observações etnográficas. Percebe-se que nos rituais de Quimbanda a experiência religiosa imanente é exacerbada, contribuindo para a produção da eficácia simbólica e da satisfação dos seus frequentadores; os seus participantes desfrutam da liberdade de por em prática uma performance religiosa suscetível de expressarem seus atributos, qualidades e dons pessoais; no espaço social e ritualístico da Quimbanda pode-se experimentar uma sociabilidade que agrega dimensões subjetivas e simbólicas produtoras de sentido para os seus membros, além de lhes permitir expressarem coletivamente o que são individualmente, em termos de opções sexuais, étnicas e sociais. Enfim, a Linha-Cruzada constitui uma 
religião prática, pragmática, de serviço, especializada nas soluções simbólicas das aflições produzidas pela vida moderna.

\section{A explicitação social do pertencimento afro-religioso}

Dizíamos acima que nos Censos 2000 e 2010 do IBGE o Rio Grande do Sul despontou como o estado da federação em que houve a maior explicitação de pertencimento identitário ao campo afro-religioso.

Entendemos que não há uma explicação, mas um conjunto de elementos que podem ajudar a compreender a exteriorização gaúcha do pertencimento ao campo religioso afro-brasileiro. Tais elementos se inscrevem na história e na cultura religiosa rio-grandense. ${ }^{8}$

Em primeiro lugar, não é destituído de sentido o fato de a diversidade religiosa estar implantada neste Estado há um longo tempo. Por exemplo, o luteranismo se implantou e aqui foi admitido a partir de 1824, com a vinda dos imigrantes alemães, que povoaram várias regiões. Este fato, produziu como efeito uma certa predisposição cultural de aceitação da alteridade religiosa e de convivência inter-religiosa. Embora a relação entre as religiões não tenha sido sempre pacífica, o fato é que o pluralismo religioso iniciou no Rio Grande do Sul muito antes do que em muitas outras regiões do país, onde o catolicismo se manteve não somente hegemônico como também exclusivista até pouco tempo atrás. Evidentemente que há uma distância social e simbólica entre luteranismo e outras religiões, sobretudo as de matriz africana. Porém, a fixação do luteranismo de certa forma abriu espaço para que os indivíduos pertencentes a outras religiões, entre as quais as afro-brasileiras, pudessem também cultivar a sua religião e explicitá-la socialmente.

Em segundo lugar, há no Rio Grande do Sul uma tradição de afirmação social das opções individuais, que geram identidades e alteridades, nos campos da política, das ideologias, do esporte. Se, por um lado, historicamente essa situação tem gerado tensões e conflitos, até mesmo belicosos, por outro, ela incide também no campo religioso, predispondo os indivíduos a também expressarem social e publicamente suas opções e convicções religiosas, entre elas, a afro-religiosa.

Em terceiro lugar, no Rio Grande do Sul as religiões afro-brasileiras parecem ser menos estigmatizadas do que em outras regiões do país, o que facilita a adesão das pessoas, não inibindo-as de expressarem socialmente tal pertencimento. Esta proposição é sugerida a partir de considerações de

Portanto, fica claro que, na sequência, adiantaremos não as razões da aproximação e da adesão dos habitantes do Rio Grande do Sul às religiões afro-brasileiras, mas as razões da explicitação social do pertencimento a essas religiões. Sobre o primeiro tópico ver Oro, 1988. 
R. Prandi, segundo o qual haveria uma relação entre maior e menor preconceito contra as religiões afro-brasileiras e mais longa ou mais recente implantação das mesmas nas diferentes regiões brasileiras (Prandi, 2003). Assim sendo, pode-se inferir que uma relativa atenuação do preconceito contra as religiões afro-gaúchas pode estar vinculada ao fato delas terem sido de fato constituídas neste Estado mais recentemente do que em outras regiões brasileiras, embora, como disse, há indícios de sua presença em solo gaúcho ainda no século 19.

Enfim, embora as religiões afro-brasileiras implantadas no Rio Grande do Sul tenham sido, em sua origem, religiões étnicas, como no resto do país, a memória histórica que vigora neste meio religioso sugere que vem de longa data a integração nele de indivíduos "brancos", pertencentes a outros segmentos étnicos, enquanto clientes, simpatizantes e membros, mas, também, como agentes e líderes religiosos. Este fato contribuiu, até certo ponto, para uma maior legitimação e aceitação social das religiões afro-brasileiras, ao mesmo tempo em que colaborou tanto para que houvesse uma redução dos estigmas depreciativos contra elas - embora aqui eles também existam - quanto para que os seus fiéis pudessem divulgar socialmente este seu pertencimento religioso.

\section{Conclusão}

As religiões afro-brasileiras existentes no Rio Grande do Sul constituem um complexo religioso, com destaque para o batuque (ou nação), a umbanda e a linha cruzada (ou quimbanda). Se, para dentro desse meio religioso, as duas primeiras expressões religiosas historicamente acomodaram-se com alguma facilidade, a última foi e continua sendo motivo de controvérsias e de severas contendas internas. Mesmo assim, para fora do campo religioso, tais religiões conquistaram relativa aceitação social, a tal ponto que seus membros tendem menos a se esconder atrás do sincretismo católico e mais a expressarem socialmente este seu pertencimento religioso. Como consequência disso, o Rio Grande do Sul, embora sendo considerado "branco", tornou-se, no país, o Estado que acolhe o maior número de indivíduos que se consideram pertencentes às religiões afro-brasileiras. Se, como vimos, por um lado, isto se deve a contingências históricas e culturais próprias deste Estado, por outro, acrescentamos agora, isto se deve, também, ao histórico esforço político conduzido pelos seus líderes religiosos e membros filiados no sentido de enfrentarem o preconceito racial, a intolerância religiosa e os estigmas depreciativos. É desta forma que no Rio Grande do Sul, reproduzindo, até certo ponto, o que ocorre no resto do país, as religiões afro-brasileiras tornaramse universais, multiétnicas, transclassistas e transnacionais. Ou seja, elas constituem uma alternativa religiosa aberta e receptiva a todos os indivíduos, 
independentemente de sua origem social e étnica, e se expande para outros países, sobretudo os que fazem fronteira com o Rio Grande do Sul, como a Argentina e o Uruguai (De Bem, 2007; Frigerio, 1989; Frigerio e Carozzi, 1993; Pi Hugarte, 1997; Oro, 1999).

\section{Referências}

ALVES, Lindomar. Orixás: uma obra do afro-gaúcho. Porto Alegre: Edição do Autor, 2009.

BRAGA, Reginaldo Gil. Batuque Jêje-Ijexá em Porto Alegre. A música no Culto aos Orixás. Porto Alegre: FumProarte, Secretaria Municipal da Cultura de Porto Alegre, 1998.

CORREA, Norton. O batuque gaúcho. História Viva. Cultos Afro. Porto Alegre, 2007. p. 56-57.

CORREA, Norton. O batuque no Rio Grande do Sul. Porto Alegre: Ed. da Universidade/ Ufrgs, 1992.

CORREA, Norton. Os vivos, os mortos e os deuses. Porto Alegre. Dissertação (Mestrado em Antropologia Social) - Programa de Pós-Graduação em Antropologia Social, Universidade Federal do Rio Grande do Sul, 1988.

CORREA, Norton. Panorama das religiões afro-brasileiras do Rio Grande do Sul. In: ORO, Ari Pedro. As religiões afro-brasileiras do Rio Grande do Sul. Porto Alegre: Ed. da Universidade/Urfgs, 1994. p. 9-46.

DE BEM, Daniel. Caminhos do Axé: a transnacionalização afro-religiosa para os países platinos a partir do terreiro de Mãe Chola de Ogum, de Santana do Livramento/ RS. Dissertação (Mestrado em Antropologia Social) - Programa de Pós-Graduação em Antropologia Social, Universidade Federal do Rio Grande do Sul, 2007.

FERNANDES, Mariana Balen. Ritual de Maçambique: religiosidade e atualização da identidade étnica na comunidade negra de Morro Alto/RS. Dissertação (Mestrado em Antropologia Social) - Programa de Pós-Graduação em Antropologia Social, Universidade Federal do Rio Grande do Sul, 2004.

FRIGERIO, Alejandro. Umbanda e Africanismo em Buenos Aires: duas etapas de um mesmo caminho religioso. Comunicações do Iser, n. 35, p. 52-63, 1989.

FRIGERIO, Alejandro; CAROZZI, Maria Julia. Las religiones afro-brasileñas en Argentina. Cadernos de Antropologia. PortoAlegre, PPGAS/Ufrgs, n. 10, p. 39-68, 1993.

LAYTANO, Dante de. Os africanismos no Dialeto Gaúcho. Revista do Instituto Histórico e Geográfico do Rio Grande do Sul, Porto Alegre, II trimestre do ano XVI, 1936.

LIRIO DE MELLO, Marco Antonio. Reviras, Batuques e Carnavais. A cultura de resistência dos escravos em Pelotas. Pelotas: Editora da UFPel, 1995.

ORO, Ari Pedro. Axé Mercosul. As religiões afro-brasileiras nos paises do Prata. Petrópolis: Vozes, 1999.

ORO, Ari Pedro. Negros e brancos nas religiões afro-brasileiras no Rio Grande do Sul. Comunicações do ISER, v. 28, p. 33-54, 1988. 
ORO, Ari Pedro. Religiões afro-brasileiras do Rio Grande do Sul: passado e presente. Estudos Afro-Asiáticos, ano 24, n. 2, p. 345-384, 2002.

ORO, Ari Pedro. As religiões afro-gaúchas. In: SILVA, Gilberto Ferreira da; SANTOS, José Antônio dos; CARNEIRO, Luiz Carlos da Cunha (Orgs.). RS Negro. Cartografias sobre a produção do conhecimento. Porto Alegre: Edipucrs, 2008. p. 123-133.

PI HUGARTE, Renzo. Transnacionalização da religião no Cone-Sul: o caso do Uruguai. In: ORO, Ari Pedro; STEIL, Carlos Alberto (Orgs.). Globalização e Religião. Petrópolis: Vozes, 1997. p. 201-218.

PRANDI, Reginaldo. As religiões afro-brasileiras e seus seguidores. In: Civitas, Porto Alegre: PUCRS, v. 3, n. 1, p. 15-34, jun. 2003.

SANTOS, Jocélio Teles dos. Mapeamento dos terreiros de Salvador. Salvador: UFBA, Centro de Estudos Afro-Orientais, 2008.

SILVA, Maria Helena Nunes da. O Príncipe Custódio e as religiões afro-gaúchas. Dissertação (Mestrado em Antropologia) - Universidade Federal de Pernambuco, 1999.

SILVA, Vagner Gonçalves da (org). Intolerância religiosa. Impactos do neopentecostalismo no campo religioso afro-brasileiro. São Paulo: Edusp, 2007.

Data de recebimento: 03.10 .2012

Data de aprovação: 15.10 .2012 